\title{
CHRISTIAN THOMASIUS, EL ESTADO DE DERECHO Y LA SEPARACIÓN ENTRE IGLESIA Y ESTADO*
}

\author{
POR \\ JOHN CHRISTIAN LAURSEN ${ }^{1}$ \\ University of California
}

\begin{abstract}
RESUMEN
Christian Thomasius fue, ante todo, un profesor de Derecho que utilizó su formación jurídica para resolver todo tipo de problemas legales, políticos y morales. En este artículo veremos que dos de sus escritos plasmaron parte de su contribución a la articulación de las relaciones apropiadas entre religión y política en la modernidad. Asimismo, utilizó el incipiente concepto de Estado de derecho (rule of law) para defender a Denis Veiras, autor de la Histoire des Sevarambes, de la acusación de ateísmo. Del mismo modo, defendió la jurisprudencia escéptica de Georg Heber como el mejor instrumento para separar la Iglesia del Estado, y se valió de la teología escéptica para justificar la exclusión de los teólogos de la política y contener la intervención de los príncipes en asuntos religiosos, salvo en los casos en que estuviese en juego la paz política.
\end{abstract}

PALABRAS CLAVE: Christian Thomasius; Estado de derecho; separación de la Iglesia y el Estado; modernidad.

\section{CHRISTIAN THOMASIUS, THE RULE OF LAW, AND THE SEPARATION OF CHURCH AND STATE}

\begin{abstract}
Christian Thomasius was above all a professor of jurisprudence who used his legal skills to resolve all sorts of legal, political, and moral problems. In this article we review two of his writings that contributed to his rearticulation of the relations between religion and politics in early modernity. He used the elements of what later became the concept of the rule of law to defend Denis Veiras, author of the Histoire des Sevarambes, against charges of atheism. He also defended the skeptical jurisprudence of Georg Heber as the best instrument for separating church and state and assigning each their proper roles, and made use of theological skepticism to justify excluding the theologians from politics and limit the interventions of princes into religious matters except in cases where the peace of the state was endangered.
\end{abstract}

KEY WORDS: Christian Thomasius; Rule of law; Separation of Church and State; Modernity.

Cómo CITAR ESTE ARTículo / CITATION: Laursen, J. C. 2018. "Christian Thomasius, el Estado de derecho y la separación entre Iglesia y Estado». Hispania Sacra 70, 141: 105-113. https://doi.org/10.3989/hs.2018.010

\section{Recibido/Received 05-09-2017 \\ Aceptado/Accepted 05-10-2017}

El presente ensayo estudia las contribuciones de Christian Thomasius (1655-1728) a la religión y la modernidad política. Thomasius fue profesor de Derecho en Leipzig entre 1681 y 1690, y después en Halle entre 1694 y 1728, y utilizó su formación jurídica y filosófica para resolver problemas jurídicos, políticos y morales. En una extensa reseña de 1689, desarrolló conceptos incipientes que posteriormente se convirtieron en elementos reconocidos de la teoría del Estado de derecho para defender al autor Denis Veiras

\footnotetext{
* Artículo editado por Marta García Alonso.

1 johnl@ucr.edu/ORCIDiD: http://orcid.org/0000-0003-0028-4149
}

de las acusaciones según las cuales su libro, Histoire des Sevarambes, era ateo. En 1693, publicó, proclamándolo el mejor método para separar la Iglesia del Estado, el anuncioprograma de un curso sobre jurisprudencia escéptica de Georg Heber en el que éste argumentaba que los teólogos debían ser excluidos de la política y los líderes políticos debían evitar implicarse en asuntos religiosos, a menos que éstos afectasen a la paz. Ambos puntos coinciden con los estudios recientes sobre Thomasius, pero lo que resulta nuevo e innovador en mi trabajo es el uso de textos que no han sido examinados previamente en ningún estudio. 


\section{EL ESTADO DE DERECHO}

Está generalmente aceptado que Thomasius era un devoto luterano. Sin embargo, escribió con profusión contra la práctica generalizada de acusar a personas de ateísmo, herejía, brujería y otras desviaciones de la ortodoxia cristiana. Uno de estos escritos fue una defensa del autor de la Histoire des Sevarambes (1675-1679) contra las acusaciones de ateísmo. ${ }^{2}$ Ésta tomó la forma de una extensa reseña de la traducción alemana del libro en la recién nacida revista de Thomasius, Freymüthiger Jedoch Vernunfft und Gesetzmässiger Gedankken (Conceptos Cándidos pero Razonables y Legítimos), conocida como Monats-Gespräche, en $1689 .^{3}$

Evidentemente, la defensa por parte de Thomasius de un autor que había sido acusado de ateísmo no pretendía fomentar el ateísmo o cualquier otra corriente de libertinismo filosófico. Más bien formaba parte de la lucha que sostuvo toda su vida por distinguir las esferas de la política y el Derecho de la esfera de la teología, y por limitar el poder del clero más allá de su autoridad legítima en asuntos religiosos. ${ }^{4} \mathrm{El}$ presente ensayo confirma el análisis de su carrera como una dedicada a la libertad de filosofar, a limitar el poder del clero y a apoyar el derecho y el poder del príncipe en asuntos políticos. Esta campaña casi protoliberal tuvo el efecto colateral de brindar una acérrima defensa a los ateos y libertinos filosóficos contra algunos de sus peores enemigos. El principio más importante que aquí se manifiesta consiste en un ejemplo más del argumento según el cual que alguien luche por hacer el mundo moderno seguro para los ateos y los libertinos no significa necesariamente que dicha persona sea atea o libertina. En ocasiones, los abogados modernos se limitan a defender al acusado y no abogan positivamente por una causa.

Thomasius se doctoró en Derecho y comenzó a enseñar jurisprudencia natural en la Universidad de Leipzig en 1679. Sus primeras obras dignas de atención fueron Introductio ad philosophiam aulicam (Introducción a la Filosofía Áulica) e Institutiones jurisprudentiae divinae (Instituciones de Jurisprudencia Divina), ambas de 1688. Algunas citas de su Institutiones nos ayudarán a entender su actitud hacia el ateísmo ${ }^{5}$, que dimanaba de su principio general de libertad filosófica. Thomasius insiste en que defiende el «principio de la libertad de filosofar» y enseña "presentando argumentos de ambas partes de la controversia», aunque al final exponga su propia posición. ${ }^{6}$ En asuntos intelectuales, dice, «nada resulta más dañino que el prejuicio a favor de la autoridad establecida». ${ }^{7}$ A continuación, estudiaremos

\footnotetext{
2 Parte del presente debate se inspira en Laursen 2017: 403-416. Sobre Veiras, véase Laursen y Pham 2017: 427-442.

3 Thomasius 1689: IV, 949-1005; reimpreso en Veiras 1990: 76*-118*. El texto de Veiras se reproduce en las páginas 1-362 del volumen editado por los Braungart. Las obras secundarias en respuesta de Veiras han sido reproducidas con números con asteriscos (páginas $\left.x x^{*}-x x^{*}\right)$, y se citan a menudo a continuación.

4 Véase Hunter 2007; ibídem 2005: 155-167; ibídem 2001; Holzhey y Zurbuchen 2001: 1165-1202.

5 Thomasius 2011. Este título fue el precursor de la obra más madura de Thomasius Fundamenta luris Naturae et Gentium (1705), traducida como Thomasius 1994a. Su obra tardía Paulo Plenior Historia Juris Naturalis (1719) también fue traducida al español como Thomasius 1998.

6 Thomasius 2011: 11.

7 Ibídem: 14.
}

cómo negocia exactamente los límites adecuados de dicha libertad en el caso concreto de Veiras.

En la disertación introductoria a su Institutiones, Thomasius señala que tuvo que aprender por sí mismo "cómo separar las cuestiones teológicas de las cuestiones filosóficas». ${ }^{8}$ Al hacerlo, había advertido que "muchas visiones se mantenían por la opinión unánime de los teólogos, y se consideraban generalmente asuntos teológicos, a pesar de que no pertenecieran al ámbito de la teología sino al de la filosofía moral o la jurisprudencia». ${ }^{9}$ A partir de sus propios análisis de la filosofía moral y la jurisprudencia, concluyó que «el poder de declarar a alguien hereje no correspondía a individuos privados, aunque gozasen de mucha autoridad, sino al príncipe» y que "la acusación de herejía no implicaba necesariamente el crimen de herejía, visto que además se abusaba terriblemente tanto de este último término como del de hereje». ${ }^{10}$

Thomasius observa que «vivía en un siglo en que no pocas personas consideraban su deber impedir la libertad de debate filosófico», en parte porque "sienten, con bastante acierto, que la libertad de debate filosófico socavó gravemente la autoridad de los filósofos sectarios» (en referencia a los aristotélicos, los tomistas, etc.). ${ }^{11}$ Cuando sus argumentos filosóficos son refutados, «creen que defienden mejor su causa si persuaden a la gente mediante el pretexto de la religión de que [...] actúan bajo la guía de Dios y luchan por defender la piedad, y si acusan a sus adversarios de ser ateos, herejes, personas impías e innovadores imprudentes $"{ }^{12}$ No cabe duda de que Thomasius era anticlerical; sin embargo, esto no significa que fuese antirreligioso, sino simplemente que estaba a favor de ceder el poder al príncipe secular en asuntos políticos y jurídicos. Afortunadamente, "[vivió] bajo el reinado de un príncipe justo, con la capacidad y la voluntad de proteger a los inocentes» de dichas acusaciones. ${ }^{13}$

Sobre la cuestión concreta del ateísmo, Thomasius señala que ha probado "que el ateísmo es directamente contrario a los principios que demostré». ${ }^{14}$ Al final del libro I, afirmaba que «aquellos que niegan los principios presentados hasta ahora en relación con Dios son llamados ateos» y que "aquél que niega la existencia de Dios destruye el fundamento de toda moral». ${ }^{15}$ En consecuencia, en esta introducción puede argumentar que fue acusado de ateísmo únicamente debido a sus «esfuerzos por preservar los límites estrictos que separan la sacrosanta teología de la sabiduría humana». ${ }^{16}$ Se da el caso de que "muchas de las cuestiones y afirmaciones empleadas habitualmente por los teólogos [...] no son propiamente teológicas, sino filosóficas o jurídicas» y, por consiguiente, no se encuentran bajo la jurisdicción de los teólogos. ${ }^{17}$ Señaló en numerosas ocasiones que la gente acusaba a sus oponentes de

\footnotetext{
8 Ibídem: 3.

9 Ibídem: 6.

10 Ídem.

11 Ibídem: 18-19.

12 Ibídem: 19.

13 Ídem.

14 Ibídem: 21.

15 Ibídem: 126.

16 Ibídem: 21.

17 Ibídem: 22.
} 
ateísmo porque no podía rebatir sus argumentos. ${ }^{18}$ Por lo tanto, «creo que el poder de declarar a alguien hereje no corresponde ni a individuos privados ni al clero, sino que es un derecho real y compete al derecho del príncipe en asuntos sagrados». ${ }^{19}$ Esta afirmación constituye un doble ataque a los acusadores de herejía y ateísmo: por un lado, niega que él sea un ateo; por el otro, niega que los teólogos tengan derecho a acusarle de serlo. Formaba parte de la lucha que sostuvo toda su vida por asignar estos asuntos al príncipe y negar cualquier derecho del clero sobre ellos. ${ }^{20}$

De nuevo cabe observar que rechazar acusaciones irresponsables y no autorizadas de ateísmo no necesariamente implica que el autor esté defendiendo el descreimiento. Thomasius hace numerosas referencias a Dios y el Creador a lo largo de sus textos, y no hay ningún motivo para pensar que no sean sinceras. La propia intención formulada en el título de Institutiones, la definición de la jurisprudencia divina, asume su existencia. El «primer principio de la jurisprudencia divina» es "'Obedece a Dios'». ${ }^{21}$ No existe ninguna razón para pensar que está siendo irónico cuando afirma que "Dios me ha encomendado decir la verdad, en particular al clero». ${ }^{22}$ En su Institutiones, hace referencia al "veneno del ateísmo», y declara que "aquél que niega la existencia de Dios destruye el fundamento de toda moralidad ${ }^{23}$ Cuando Thomasius defiende a aquellos que han sido acusados de herejía, ateísmo y espinosismo, lo hace siempre desde el punto de vista de un cristiano. Ningún estudioso de Thomasius ha sugerido nunca que fuese secretamente ateo o libertino.

Los límites precisos del cristianismo de Thomasius han sido objeto de intensos debates, y fueron evidentemente inestables. Alrededor de 1689, sus opiniones en materia religiosa parecen coincidir con las de Philipp Jakob Spener, a menudo considerado el fundador del pietismo alemán, cuya Pia desideria fue publicada en $1675 .{ }^{24}$ Más tarde, afirmó que el libro más bien heterodoxo de Gottfried Arnold sólo era superado en utilidad por la Biblia. ${ }^{25}$ Este hecho ha sido considerado como parte del viraje de Thomasius hacia lo que entonces se conocía como una forma más entusiasta de religión, cercana al milenarismo, antes de virar de nuevo fuera de ella. ${ }^{26}$ Sin embargo, como ya se ha dicho, nadie sostiene que simpatizase nunca con el ateísmo o el espinosismo.

Es cierto que, a lo largo de su carrera, Thomasius criticó la tiranía filosófica y teológica. No obstante, ello no equivale a realizar una defensa filosófica del ateísmo o de los derechos individuales. Como ha argumentado lan Hunter, la «filosofía sectaria» que Thomasius siempre combatió incluía tanto el aristotelismo escolástico como el platonismo cristiano, el cartesianismo o el espinosismo. No pretendía

18 Véase Thomasius 1994b: 11. Citado de Diskurs von der Freiheit der itzigen Zeiten gegen die vorigen «Discurso sobre la libertad de los tiempos presentes en comparación con los anteriores»; e ibídem: 22. Citado de «De praejudiciis», en Einleitung zur Vernunftlehre.

19 Thomasius 2011: 22.

20 Véanse los textos reunidos en Thomasius 2007.

21 Thomasius 2011: 118-119.

22 Citado en Hunter 2007: 1.

23 Thomasius 2011: 104 y 126.

24 Ahnert 2006: 28.

25 Citado en Ahnert 2006: 63, 147n.32.

26 Ahnert 2006: passim crear una filosofía alternativa "que pueda rivalizar con el aristotelismo, el cartesianismo o el espinosismo", sino «impedir la mezcolanza entre la filosofía y la teología». ${ }^{27}$ Por lo tanto, Thomasius podía defender a los ateos y espinosistas de la persecución por motivos religiosos y al mismo tiempo atacarles por errores intelectuales. Cuando argumentaba en Cautelen zur Erlernung der Rechtsgelehrtheit (1713) que debía tolerarse al "ateo teorético» Spinoza, su tolerancia no se basaba en lo que Hunter ha llamado una "defensa racionalista de la libertad intelectual y religiosa», y en modo alguno constituía una defensa del racionalismo ateo de Spinoza. ${ }^{28}$ Para Thomasius, lo que de verdad importa es aquello que beneficia a la paz y la justicia. Por lo tanto, no era liberal al estilo de Locke, sino en el sentido que apoyaba un Estado secular sin ideología y sin teología. Como dice Hunter, derivaba «libertades y derechos protoliberales del ejercicio absolutista del poder del príncipe». ${ }^{29}$ La tolerancia del disentimiento religioso no sería un derecho personal del disidente, sino un derecho del príncipe, quien puede hacer uso de él para aplacar la exaltación religiosa si y sólo si considera que sería una política civil efectiva. ${ }^{30}$

Thomasius comienza su artículo sobre la obra Histoire des Sevarambes resumiendo el argumento y concluye que "causará una gran satisfacción a todas las personas libres de prejuicios». ${ }^{31}$ Señala que el autor es desconocido, pero que "un buen amigo» le dijo que en Francia se creía que era un tal "Monsieur D’Allais» (también conocido como Denis Veiras, Sieur D'Allais). ${ }^{32}$ Entre otros hechos de la biografía del autor que contribuían a hacer probable esta hipótesis se hallaban que Veiras hablaba inglés (la lengua de la primera versión de las dos primeras partes) y que era el autor conocido de Grammaire Méthodique (1682), que contenía materiales que recordaban mucho al cuarto volumen de Histoire. ${ }^{33}$ En lo que se refiere a su religión, «no era un ferviente papista sino más bien un cristiano sensato, y hablaba libremente contra los papistas»; era protestante y huyó a Inglaterra porque no quería cambiar su religión. ${ }^{34}$

Thomasius cree que el autor de la Histoire era un buen protestante, pero menciona que otros no comparten esta opinión. Cita la obra Polyhistor de Daniel Morhof de 1688 como ejemplo de acusación al autor de ser un ateo y naturalista que pone en duda la Trinidad y el cristianismo y atribuye milagros como aquellos del Pentateuco al impostor Stroukaras. ${ }^{35}$ Pero Morhof no es el único, ni entonces ni ahora, en acusar a Veiras de ateísmo. En 1697, Pierre Bayle señaló que "el autor de Histoire» no carecía de una cierta "sutileza (finesse)» para conseguir que sus ideas subversivas superasen la censura. ${ }^{36}$ En 1711, Christoph August Heumann observó que el libro dotaba de argumentos a los ateos y los naturalistas. ${ }^{37}$ Fabricius (en 1716), Reimann (en 1725) y Trinius (en 1759) fueron tan sólo algunos de los autores

\footnotetext{
27 Hunter 2007: 77; véase también 13.

28 Ibídem: 73.

29 Ibídem: 17-18.

30 Ibídem 2007: 140.

31 Thomasius 1689: 962

32 Ibídem: 963.

33 Ibídem: 963 y 967.

34 Ibídem: 964-966.

35 Ibídem: 968-969.

36 Bayle 1990: 989.

37 Heumann 1990.
} 
que subrayaron los aspectos antirreligiosos de la historia. ${ }^{38}$ Hace pocos años, Jonathan Israel se refirió al libro como una «novela espinosista» debido a su crítica de los milagros, su materialismo y su énfasis en la libertad de pensamiento. ${ }^{39}$ Cyrus Masroori lo ha llamado «uno de los ataques al cristianismo más incisivos y osados de su tiempo $"{ }^{40}$

Las palabras de Morhof pretendían atacar a Thomasius, quien pasó gran parte de su carrera luchando contra el clero y los teólogos a favor de una religión pía y sencilla y de la responsabilidad del Estado en materia de paz y orden. "Vivimos en una época en la que se acusa demasiado frecuentemente a personas inocentes de ser herejes, cuáqueros o ateos», escribe en su reseña del libro de Veiras, recordando a sus propios libros de $1688 .{ }^{41} \mathrm{Al}$ igual que sucede con otros muchos errores, estas acusaciones a menudo son fruto de un razonamiento marcado por el apresuramiento y la aceptación de juicios ajenos y de una voluntad marcada por el amor interesado por la infalibilidad. ${ }^{42}$ Muchas personas consideran ateas a otras debido a asunciones apresuradas acerca de los criterios del ateísmo que no resisten un examen más minucioso. ${ }^{43}$ Sin embargo, Thomasius pretende guiarse por el principio interpretativo según el cual no se debe considerar que alguien sea culpable de los crímenes más graves sin que existan claros indicios de dicho crimen. ${ }^{44} \mathrm{Al}$ hacerlo, está exigiendo uno de los elementos del gobierno de la ley (rule of law): pruebas, no sólo conjeturas. Esto formaba parte de lo que Hunter ha llamado su «cultivo autoconsciente de una imagen concreta: la del intelectual público antiescolástico». ${ }^{45}$

En primer lugar, Morhof acusa al autor de History de negar la Trinidad y el cristianismo. Actuando, por así decirlo, como abogado de Veiras, Thomasius lamenta de entrada que Morhof no señalase los loca (lugares), es decir las páginas exactas que justifican su acusación. ${ }^{46}$ Thomasius deberá, por lo tanto, suponer que lo que tenía en mente eran principalmente los capítulos 15 y 16 de la parte 3 y el capítulo 11 de la parte 4 de la edición alemana. ${ }^{47}$ En consecuencia, parafrasea la página 246 de este volumen, en la que se cuenta que en esta nación existían muchas opiniones diferentes acerca de Dios ampliamente toleradas, y que uno podía incluso manifestar sus creencias en debates públicos, siempre que actuase con respeto, llevase una vida virtuosa y se ajustase a cualquier forma de culto externo requerido por la ley. ${ }^{48}$ Según explica Thomasius, no se preguntaba a los candidatos a cargos públicos acerca de su religión, sino

38 J. A. Fabricius, Bibliogaphia antiquaria (Hamburgo, 1716: 502, reproducido en Veiras 1990: $\left.125^{*}-126^{*}\right)$; J. F. Reimann, Historia universalis atheismi et atheorum (Hildesheim, 1725: 483-484, reproducido en Veiras 1990: $127^{*}-128^{*}$ ); J. A. Trinius, Freydenker Lexicon (Leipzig, 1759: 502 y 592, reproducido en Veiras 1990: 158*). Para más ejemplos, véase Veiras 1990: $129 *-138 *$

39 Israel 2001: 591-592 y 597. El gobierno absolutista que Veiras respaldaba y los límites que establecía a la libertad de pensamiento socavan la tesis de que era plenamente espinosista.

40 Masroori 2012: 124.

41 Thomasius 1689: 969.

42 Ibídem: 969-970.

43 Ibídem: 970.

44 Ibídem: 971.

45 Hunter 2007: 4.

46 Thomasius 1689: 971.

47 Veiras 2006: 301-309, 353-359.

48 Thomasius 1689: 972. acerca de su piedad y sus buenas costumbres, y ni siquiera los curas tenían vetado ocupar cargos mundanos. ${ }^{49}$ Por lo que sabemos de la actitud general de Thomasius hacia la religión, es seguro que aprobaba plenamente esta política. ${ }^{50}$

En este punto, Thomasius comienza a citar fragmentos importantes del texto de Veiras. Las páginas 972-980 de la reseña simplemente citan pasajes largos de las páginas 247-256 de la edición alemana, omitiendo algunos párrafos. En otras tierras, la religión es un pretexto para atrocidades inhumanas, pero en Sevarambia nadie puede oprimir a otra persona en razón de su religión; nadie acumula grandes riquezas, dado que son inútiles; todas las personas pueden pensar lo que deseen, pero no pueden perturbar la paz general so pretexto de sus creencias; la religión del Estado depende más de la filosofía y la razón humana que de la revelación y la fe. La secta cristiana «herética» de Sevarambia utiliza razonamientos vanos para defender su interpretación reductora de la Trinidad, rechazando la concepción católica. Más adelante, Thomasius pide al lector imparcial que juzgue si el autor pone en duda la Trinidad o más bien expresa su discrepancia de las críticas y declara coherentemente que la razón por la que los sevarambianos desconocen la Trinidad es que no conocen la revelación. ${ }^{51}$ Por su parte, los cristianos giovanitas de Sevarambia (cristianos de la época de la fundación por parte del conquistador y tutor de Sevarias, el veneciano Giovanni) cuentan que los no cristianos se burlan de sus milagros, pero los toleran. ${ }^{52}$ Los giovanitas creían que Sevarias honraba a Moisés y Jesucristo, y que el cristianismo era una religión muy adecuada para civilizar un continente corrupto como Europa, pero que no era necesario en Sevarambia. ${ }^{53}$ Por un lado, esto podría interpretarse como una crítica libertina y atea del cristianismo; por el otro, es probable que se acercara a las opiniones del propio Thomasius.

Las páginas 980-988 citan fragmentos largos del discurso de Scromenas omitiendo ciertas partes. ${ }^{54}$ La verdadera honorabilidad no residiría en las apariencias externas, sino en la justicia, el buen gobierno, una moral intachable, el amor y la caridad. La religión surgió de la curiosidad y la contemplación, y a algunos hombres sabios les sobrevino la idea de un ser superior, que identificaron con el sol. Así, la adoración del sol mediante ceremonias sencillas fue la religión más antigua existente. Sin embargo, más tarde la avaricia y la ambición dieron lugar a miles de supersticiones y ridículos nuevos ritos que la costumbre sancionó. Estos errores se combinaron con enseñanzas paganas y tiránicas para corromper los corazones de las gentes. Todo esto, por supuesto, podría constituir una crítica protestante del catolicismo. No obstante, dice Scromenas, gentes de todas las épocas y todos los lugares han utilizado estas doctrinas para hacer crecer su propio partido en detrimento de la justicia y la humanidad. Por ello, se hacía necesario que un Estado bien regulado protegiese la libertad natural de cada persona. Además, dado que la fe no es una cuestión de elección, y que generalmente tenemos razones para

\footnotetext{
49 Ídem.

50 Véase Ahnert 2006: passim.

51 Thomasius 1689: 990.

52 Ibídem: 978.

53 Ibídem: 979.

54 Ibídem: 980-988.
} 
creer en lo que creemos, cuando cambiamos de fe nos corresponde exponer los motivos por los que lo hacemos. De otro modo, podría atribuirse cualquier conversión al interés o el engaño. Una de las conclusiones que se desprende de esto es que alguien puede pasar de religiones menos racionales a religiones más racionales de buena fe, pero no lo contrario. De esta manera, personas de otras religiones podían adoptar la religión sevarambiana, pero los sevarambianos no podían adoptar otras.

Thomasius también cita pasajes del debate de Veiras sobre los giovanitas. De acuerdo con los criterios de los demás cristianos, éstos eran considerados manifiestamente herejes, dado que creían que Jesús, antes de nacer de la Virgen, no era un dios sino tan sólo un ángel, lo cual constituye una interpretación heterodoxa de la Trinidad. ${ }^{55}$ Es entonces cuando Thomasius pregunta si referir dichas ideas, insistiendo en que se trata de herejías, equivale a que el autor esté fomentando la herejía. ${ }^{56}$ La respuesta de Thomasius es "no». El autor ha afirmado expresamente que la religión sevarambiana se basaba en la razón y, por consiguiente, era irrefutable sin una revelación. ${ }^{57}$ No existe ningún argumento válido, dice Thomasius, para sostener que, por respeto al cristianismo, nadie debería ni tan siquiera imaginar una religión así. ${ }^{58}$ Visto que se permite a los poetas y cantautores hablar de dioses no cristianos, a pesar de que son incuestionablemente más peligrosos que esta ficción, no cabe duda de que esa misma libertad es aplicable al presente caso. ${ }^{59}$ En otra ocasión, Veiras cuenta que los sevarambianos se burlan de las fábulas griegas; nosotros podríamos hacer lo mismo. ${ }^{60}$

A continuación, Thomasius explica que, al parecer, Morhof también consideraba que las historias de los engaños de Stroukaras eran en realidad analogías veladas de los milagros de los libros de Moisés. ${ }^{61}$ Por ello, Thomasius resume los falsos milagros de Stroukaras y sus apoteosis y escribe que, sin embargo, ésta es una analogía improbable, ya que en ese caso las descripciones de los milagros del Diablo también implicarían dicha analogía. ${ }^{62}$ El hecho de que Stroukaras sea un astuto imitador de Moisés y Jesús tan sólo ayuda a mejorar la historia. ${ }^{63}$

Thomasius concluye su reseña afirmando que, en la inmensa mayoría de los casos, las personas acusan a otras de ateísmo por odio al prójimo o por amor propio. ${ }^{64}$ El Estado de derecho debería imposibilitar esta clase de acusaciones tendenciosas. Por ejemplo, los autores de L'Art de penser de Port Royal acusan a Montaigne de libertinismo, sacando de contexto sus escritos y exponiendo así su mala fe..$^{65}$ Las últimas páginas refieren otro caso de acusación insensata de ateísmo, y el autor renueva sus críticas a los hipócritas que proclaman su infalibilidad. ${ }^{66}$ Algunos años más tarde, en

\footnotetext{
55 Ibídem: 989.

56 Ibídem: 990.

57 ídem.

58 Ídem.

59 Ibídem: 991.

60 ídem.

61 Ibídem: 992.

62 Ibídem: 997.

63 Ídem.

64 Ibídem: 997-998.

65 Ibídem: 998.

66 Ibídem: 1005.
}

su Ausübung der Sittenlehre (Ética Práctica) de 1696, una de sus muchas variaciones sobre este mismo tema, Thomasius criticó la filosofía moral de las universidades luteranas y calvinistas, que enseñaban a los estudiantes a "condenar a aquellos a los que acusan de herejía. De esto se desprende que la manera de escribir y luchar contra el espinosismo, el estoicismo y el pelagianismo es lanzar acusaciones de herejía. En otras palabras, hacer una montaña de un grano de arena». ${ }^{67}$

Muchas de las nociones acerca de la religión contenidas en Histoire des Sevarambes que Morhof y otros autores consideraron ateísmo implícito eran ideas que Thomasius sin duda habría podido respaldar. Podía interpretarlas todas como un apoyo al tipo de separación de la filosofía, la teología y la vida civil que perseguía. No obstante, otros lectores menos comprometidos con el cristianismo podían interpretarlas como una batería de argumentos a favor del libertinismo, el ateísmo y la crítica de la religión. Aunque no fuesen tan minuciosos como los argumentos escépticos esgrimidos por Campanella para refutarlos ${ }^{68}$, los extractos del libro de Veiras que Thomasius recogió sin duda podrían haber alimentado la crítica libertina del cristianismo.

Sin embargo, mi conclusión es que la defensa de Veiras por parte de Thomasius no era más que eso: simplemente una defensa contra las acusaciones de ateísmo. No se trataba de un escrito a favor del ateísmo, el espinosismo o cualquier otra posición filosófica. Estaba perfectamente alineado con la lucha que Thomasius condujo toda su vida contra la mezcolanza de la filosofía, la teología y la política y contra la insensata, apresurada y desestabilizadora propensión a acusar a otras personas de crímenes de pensamiento filosófico, teológico o de otro tipo. Además, Thomasius escribió a menudo sobre Spinoza como de un autor peligroso e impío, acusando a E. W. Tschirnhaus de propagar "el veneno de Spinoza». Hunter observa que esto se debía fundamentalmente a que Spinoza asumía una concepción metafísica del conocimiento y la verdad, mientras que Thomasius creía, por el contrario, que la verdad es indiferente a la moral. ${ }^{69}$ Asimismo, éste último se oponía a la prioridad que Tschirnhaus otorgaba al conocimiento sobre el comportamiento moral, y a sus afirmaciones de que, aumentando su conocimiento, los seres humanos podían parecerse cada vez más a Dios. ${ }^{70}$ Thomasius alegó que Tschirnhaus negaba ser un espinosista precisamente para servir mejor a la causa de Spinoza. ${ }^{71} \mathrm{Sin}$ embargo, resulta importante señalar que Thomasius no criticaba a Tschirnhaus con el fin de acusarle de herejía e instar a la Iglesia a intervenir, sino para exponerle a la mofa y el ridículo como el método más adecuado para rebatir sus errores filosóficos.

El propio Thomasius era una especie de epicúreo, y también defendió a Epicuro contra las acusaciones de ateísmo. $^{72}$ Como observa Hunter, la antropología de Thomasius era epicúrea, puesto que consideraba que el

67 Thomasius, Ausübung der Sittenlehre (Halle, 1696; reimpreso en Hildesheim: Olms, 1999) (citado en Hunter I. 2001: 231).

68 Véase Paganini 2008: cap. 3.

69 Hunter 2007: 78.

70 Würtz 1981: 68 y 71.

71 Ibídem: 75.

72 Véase Gawlick 1989: 262. 
hombre era la criatura de sus pasiones. ${ }^{73}$ Pero Thomasius era un epicúreo cristiano que aplacaba las pasiones de los hombres colocando a Dios más allá de la razón, como un objeto de fe privada. ${ }^{74}$ Su filosofía moral no era atea, sino una "Affektenlehre epicúrea o doctrina de las pasiones» cristiana. ${ }^{75}$ En realidad, se trataba de una psicología, terapia o guía moral para entrenarse a controlar las pasiones, no una teoría acerca de lo que son o deberían ser. Todo consistía en equilibrar las pasiones entre ellas con el fin de alcanzar una calma interior. ${ }^{76}$ Rechazaba, por lo tanto, cualquier referencia a un derecho filosófico superior, una normativa superior o una justicia superior. ${ }^{77}$ Para él, la política debería consistir en el autocontrol y el refrenamiento mutuo de las pasiones. La soberanía civil no debería guardar ninguna relación con la religión, siempre y cuando las personas religiosas se comportasen adecuadamente. Sin embargo, Thomasius seguía siendo un cristiano, y el epicureísmo sólo era admisible si estaba subordinado al cristianismo.

A lo largo de la mayoría de sus obras publicadas, Thomasius insistió en que el ateísmo era algo malo. ${ }^{78}$ Así, incluso cuando defendía a un autor como Veiras contra las acusaciones de ateísmo, se mostraba absolutamente de acuerdo con la idea de que los príncipes pudieran prohibir la promoción pública del ateísmo por tratarse de un peligro para la paz. Su pensamiento posterior sobre esta cuestión siguió dos líneas generales. Una consistía en militar en contra de la criminalización de los ateos. En 1695, reconoció que podría pensarse que es «en aras de la sociabilidad que declaro ante el mundo mi reverencia interior por la Deidad como, por así decirlo, el fundamento de toda obligación, para que nadie me considere un ateo y me rehúya», creyendo que soy una amenaza para la paz social. ${ }^{79}$ Sin embargo, Thomasius pensaba que «incluso aquí, puedo indicar suficientemente mi culto interior por otros medios y por signos más fiables, es decir, observando la ley natural y cumpliendo mis deberes para con los otros hombres». ${ }^{80}$ No se precisa ninguna declaración positiva de teísmo, y el buen comportamiento se tomará como un signo de fe, de modo que un ateo que se comporta adecuadamente no debe ser castigado.

No obstante, en sus lecciones de ese mismo año (publicadas mucho más tarde), afirmaba que «un príncipe cristiano no está obligado a tolerar a un ateo ni a aquél que niega al Creador del mundo y su Providencia. En efecto, el príncipe siempre debe esperar que, si el ateo osa dar rienda suelta a sus deseos y ponerlos en práctica en secreto, no respetará las leyes y la paz de la república, sino que las perturbará».81 Sin embargo, añadió una nota en la que señalaba que no estar obligado a tolerar a estas personas no implicaba que el príncipe estuviese obligado a perseguirlas: podía decidir tolerarlas por razones de prudencia. ${ }^{82}$

En esta misma línea, Thomasius utilizó distinciones típicamente jurídicas para oponerse al hábito de ver ateos

\footnotetext{
73 Hunter 2007: 80; véase Tomasoni 2009: 44.

74 Hunter 2007: 80.

75 Ibídem: 101.

76 Ibídem: 103 y 105

77 Ibídem: 107.

78 Véase, por ejemplo, Tomasoni 2009: 81ff.

79 Thomasius 2007: 54.

80 ídem.

81 Ibídem: 273-274.

82 Ibídem: 273.
}

por todas partes. Por ejemplo, negar la existencia de la brujería y la hechicería no implica ateísmo, igual que negar la existencia del Diablo no significa negar la existencia de Dios. $^{83}$ Asimismo, Thomasius distinguía en numerosos escritos el elemento importante de creencia en Dios, el amor, de un elemento insignificante e irrelevante, la aprobación intelectual. ${ }^{84}$ Como escribe en 1724, el "ateísmo» al que más se oponía era aquél de "un ateo que ofende a su prójimo cada día con su conducta impía», no con sus ideas. ${ }^{85}$

En conferencias del período 1697-1705, publicadas en 1738 como Vollständige Erlauterung der KirchenrechtsGelahrtheit (Explicación Completa de la Jurisprudencia del Derecho Eclesiástico), Thomasius se alejó al máximo de la criminalización del ateísmo. Observaba que Spinoza y los espinosistas, "cuyo número crece cada día», "son auténticos ateos [intelectuales] $»^{86}$, pero a continuación añadía que «en el pasado, mantuve que nada podía ser más perjudicial para la república que el ateísmo. Sin embargo, hoy reconozco que esto es falso" ${ }^{87}$ Es posible que aprendiese de Pierre Bayle que los intelectuales ateos no necesariamente violaban las leyes de la moralidad y la política. ${ }^{88}$ Por lo tanto, era posible defender la descriminalización del ateísmo. El Estado de derecho no requería un control tan estricto.

La otra línea ahondaba en la criminalización del ateísmo, como por ejemplo en su polémica con Theodor Ludwig Lau. En Elender Zustand eines in die Atheisterey verfallenen Gelehrten (1720), aprobaba que se confiscase el libro de Lau. ${ }^{89}$ Sus argumentos han sido descritos como débiles e incoherentes con la mayoría del resto de su obra sobre brujas y herejía. ${ }^{90} \mathrm{Al}$ parecer, el núcleo de la cuestión era que asociaba el ateísmo espinosista con el mismo tipo de intelectualización de la religión a la que se oponía en el caso de los luteranos ortodoxos. Como Locke, podía argumentar que los ateos no podían reclamar un derecho a la libertad de expresión conferido por Dios si no reconocían a ningún dios, lo cual confirma la posición fundamentalmente basada en la religión de Thomasius. En la mayoría de su obra fue un defensor luterano de la libertad cristiana. Si ello significa que podía defender a un escritor como Veiras contra acusaciones de ateísmo, no quiere decir estrictamente que estuviese dispuesto a apoyar el ateísmo, el espinosismo y el libertinismo.

Thomasius ha sido durante mucho tiempo acusado de absolutismo, de defender un príncipe todopoderoso, y en cierto modo esta apreciación es correcta. ${ }^{91}$ También Veiras ha sido descrito como un absolutista, como un defensor de una teocracia prácticamente totalitaria, y en cierto modo también lo es. ${ }^{92}$ Por ello, no resulta sorprendente que Thomasius defendiese a Veiras contra las acusaciones de ateísmo y de debilitamiento del Estado. De hecho,

\footnotetext{
83 Ibídem: 217-218 y 229.

84 Ibídem: 170-171; Hunter 2007: 201. Véase Tomasoni 2009:

85 Thomasius 2007: 133

86 Citado en Gawlick 1989: 262.

87 Citado en Hunter 2001: 258. Véase también Hunter 2011: 139-40.

88 Thomasius menciona la obra Comet de Bayle en Thomasius

89 Gawlick 1989: 268.

90 Ibídem: $269 f f$

91 Holzhey y Zurbuchen 2001: 1202.

92 Keohane 1980: 323; Masroori 2012: 131 y 135.
} 71-122. 2007: 229. 
Thomasius reconoce que propondría políticas similares a las de Veiras, no para promover el ateísmo, sino para asegurar el control civil sobre los aspectos peligrosos de la religión.

\section{SEPARACIÓN DE LA IGLESIA Y EL ESTADO}

Un segundo elemento importante de modernidad que Thomasius promovió fue la separación entre Iglesia y Estado. Ya se ha mencionado que esto formaba parte de su programa general, y que lo veía como plenamente coherente con su luteranismo. Ahora estudiaremos una ocasión específica en la que respaldó a un autor contemporáneo que se basaba en los recursos intelectuales del escepticismo filosófico para defender la separación entre Iglesia y Estado. ${ }^{93}$ Georg Michael Heber era un contemporáneo de Thomasius que enseñaba Derecho en Wittenberg a finales del siglo XVII. ${ }^{94}$ Debemos nuestro conocimiento del programa del curso de Heber a Thomasius, quien compartía el antipedantismo de Heber, su crítica a la autoridad dogmática y determinados aspectos de su escepticismo. Heber se lo mandó a Thomasius y éste lo publicó en su Historia de la sabiduría y de la estupidez de 1693, una colección de programas de cursos y otros ensayos. ${ }^{95}$ Thomasius presentó el programa del curso de Heber junto con el siguiente comentario:

Hasta ahora pensábamos que los pirrónicos fueron los pensadores más estúpidos que hayan existido. En todo caso, eso es lo que enseñaban los profesores, hasta que incluso esta secta halló un defensor en el muy instruido escritor francés La Mothe Le Vayer. Este autor demostró que los pirrónicos, al igual que otros filósofos paganos, pudieron haber tenido un lado malo, pero también tenían un lado bueno: eran particularmente perspicaces, y capaces de defenderse contra todo el resto de manera eficaz. Eran especialmente inteligentes en que sus miembros a menudo eran estimados y participaban en el gobierno de sus ciudades. ${ }^{96}$

François de La Mothe Le Vayer revistió una gran importancia para la Ilustración de Halle. ${ }^{97}$ Aquí, Thomasius revela su preferencia por el juicio del francés en contra de la opinión comúnmente aceptada sobre el escepticismo desde la Edad Media:

Admito que el sofisma habitual por el que se defiende que es necesario combatir duramente a los escépticos para sacarles del error no sólo es inhumano, sino que además no resulta muy convincente. El escéptico tendría entonces que admitir que, puesto que está siendo criticado con tanta aspereza, algo de lo que dice

${ }^{93}$ Utilizó el escepticismo acerca de la teología para respaldar una suerte de política conservadora también en otros ámbitos: véase Laursen 2015: 193-202.

${ }_{94}$ Parte de este debate se basa en Mulsow y Laursen (e. p.). Para una biografía de Heber, véase Zedler 1732ff: vol. 13, col. $1024 \mathrm{f}$.

95 Heber 1693: 124-134.

96 Thomasius 1693: vol. II, 124. Introducción de G. M. Heber: "Stultissimos omnium habuimus Pyrrhonicos hucusque, ita videlicet a Magistris edocti, donec et haec secta in eruditissimo Gallo Mothaeo Vayerio defensorem invenerit, ac ille ostenderit, sectam hanc, uti reliquas Gentilis Philosophiae sua incommoda habuisse, sed et sua commoda, et acutissimos fuisse Pyrrhonicos, utpote qui suam sectam contra reliquas omnes non sine successu defenderint; et prudentissimos, cum ejus Sectatores cum laude saepius Gubernaculis Reipublicae praefuerint».

97 Para lo siguiente, véase Mulsow 2017: vol. II, cap. XII. debe ser cierto, o ser objeto de burla de todo el mundo si reclama que su oponente debería ser castigado sólo porque a él le parece que ha sido abusivamente criticado por aquél. ${ }^{98}$

Según Thomasius, esta actitud estaría profundamente equivocada, y no haría justicia a las sutilezas del antiguo escepticismo. El crítico del escepticismo pregunta:

¿Qué ocurriría si el escéptico siguiese su argumento hasta sus últimas consecuencias y formulase su acusación como sigue: le pareció que Titius le trató injustamente, y lo mismo les pareció a otros testigos, y, por ello, pidió que un juez ordenase que a él también le pareciese, por ejemplo, que el acusado fuese fustigado igualmente como castigo ${ }^{99}$

El crítico piensa que su ironía refuta a los escépticos, pero, ¿es así? Si se dictamina que al escéptico le parezca que su oponente ha sido tratado con rudeza, ¿̇o más probable no sería que esto requiriese que el acusado fuese tratado de ese modo en términos reales? Thomasius señala que existen estrategias para eludir la autocontradicción pragmática de la que se acusa al escéptico. Sin embargo, no desarrolla este punto. No le preocupan los escépticos epistemológicos sino otros:

A pesar de que no defenderé, ni aquí ni en ninguna otra ocasión, el partido del escepticismo, existen disciplinas en las que no cabe esperarse algo seguro más allá de las probabilidades y en las que a menudo nos vemos forzados a reconocer que no está claro lo que buscamos. Esto sucede, sobre todo, al menos a mi juicio, en la jurisprudencia, y de igual manera en el Derecho romano que en el nuestro. He expuesto muchos motivos para esto en De naevis jurisprudentiae. ${ }^{100}$

Tales afirmaciones son la base de su simpatía por las tesis de Heber. Le preocupa el problema de trabajar en un campo como el Derecho, en el que no puede determinarse ninguna verdad o error definitivo. No era fácil para Thomasius ocuparse de dichas reflexiones, en parte porque se acercaban demasiado al muy ridiculizado escepticismo y levantaban sospechas de relativismo moral. Thomasius estaba encantado de encontrar un aliado en Heber:

Incluso si mi opinión no parece ajustarse a los gustos de nuestra época, no puedo evitar imprimir el programa publicado no hace mucho tiempo por mi

98 Thomasius 1693: vol. II, 124. Introducción de G. M. Heber: «Et fateor, commune Sophisma, ut inhumanum valde, ita et non magni momenti esse, quo verberibus adversus Scepticos disputari debere asseritur, ut Scepticus injuriam vindicando, aut necesse habeat fateri, se vapulasse, adeoque aliquid verum esse, aut communi omnium risui se prostituat, ut velit alterum certo puniri, eo quod ipsi saltem videatur, quod a reo vapulaverit».

99 Thomasius 1693: vol. II, 124f. Introducción de G. M. Heber: "Nam quidsi Scepticus hypothesi inserviat suae, et libellum sic formet: Videri sibi, quod Titius ipsum verberaverit, aliisque testibus idem videri, petereque adeo, ut Judex velit id efficere, ut sibi etiam videatur, reum, v. g. fustigari?».

100 Thomasius 1693: vol. II, 125. Introducción de G. M. Heber: «Sed uti Scepticismi partes nec hic nec unquam sustinebo, ita sunt tamen quaedam disciplinae, in quibus ultra verosimilia, certi quid sperare non liceat, et in quibus saepe cogimur fateri: non liquere, quod qaerimus. Quas inter, meo quidem judicio, eminet Jurisprudentia et Romana et Nostra. Causas abunde attuli in naevis Jurisprudentiae». El libro se publicó como Christian Thomasius, De naevis jurisprudentiae romanae antejustinianeae libri duo. 
mecenas y amigo de Wittenberg, quien profesa mi misma herejía [es decir que, como Thomasius, Heber defiende una suerte de escepticismo], y proclamo públicamente que espero que la famosa Universidad de Wittenberg empiece a liberar a sus profesores de las tradiciones, y que éstos comiencen a liberarse del yugo de la más que tiránica esclavitud bajo el cual suspiran junto con el resto de universidades de Alemania. ${ }^{101}$

Thomasius esperaba claramente asignar a Heber un papel protagonista en la reforma de la Universidad de Wittenberg, que debía llevarse a cabo siguiendo aproximadamente las mismas líneas de las reformas que el propio Thomasius ya estaba planeando para Halle. Thomasius pensaba que el escepticismo de Heber podría penetrar a través de las estructuras anquilosadas de la universidad. Como anunció dramáticamente, se necesitaba un tabaco fuerte para disipar el sabor del "yugo de la esclavitud».

Hemos visto que Thomasius presentó abiertamente el curso de un pensador radical que empleaba un lenguaje drástico. Desde el inicio del programa, Heber confiesa:

Desde mi juventud temprana, y según mi carácter - desconozco bajo la guía de quién-, he estado tan alejado como es concebible del vicio de la credulidad, y nunca he permitido que los ojos de mi mente se cerrasen, dejando a los demás el privilegio de ver y saber. [...] He comprendido profundamente que el coraje y el poder de la sabiduría reside en no creer nada ciegamente. Este es el motivo por el cual, especialmente en aquellos asuntos formados por nuestro entendimiento y nuestra capacidad de juicio, y no por nuestra percepción, [127] la autoridad de ningún hombre habría podido convencerme de que algo debía ser válido si mi propia razón no se mostraba también de acuerdo. ${ }^{102}$

\section{Heber proseguía:}

Siento que tengo la razón en mí, de manera que nada con lo que los autores de ensayos a menudo ridículos magnifican hoy sus elogios del célebre y el muy célebre puede inspirar pánico sagrado en mi mente. De hecho, siento en mí una falta de afinidad tan grande con estos autores que me dolería recibir elogios de hombres que no cuentan con experiencia en estos asuntos y nacieron para la servidumbre. ${ }^{103}$

Decir que todos los contemporáneos que comenzaban sus textos con elogios corteses habían nacido para la esclavitud era mostrar desprecio por la mayoría de las convenciones de la cultura cortesana del siglo XVII:

$\mathrm{Y}$, puesto que soy consciente de que los hombres ocultan la mayoría de las cosas y las esconden en una

101 Thomasius 1693: vol. II, 125f. Introducción de G. M. Heber "Cum tamen hoc opinio mea non videatur esse ad gustum seculi, temperare mihi non potui, quin Fautoris et Amici Wittebergensis, ad eandem Haeresin inclinantis, programma non ita pridem publicatum, hic loci insererem, et bene me de incluta Universitate Wittebergensi jam sperare publico tester, quid et ibi incipiat libertas recedendi a traditis Praeceptorum, atque adeo et ipsa incipiat jugum servitutis plusquam tyrannicae, sub quo hactenus cum aliis Germaniae Academiis suspiria multa traxit, abjicere. Faxit Deus, ut Consultissimo Autori propositum bene cedat, utque Catalogo Haereticorum, quos Witeberga hactenus multos effinxit, ab aliis, sub intempestivo Zelo impotentissimos affectus tegentibus, non inseratur!».

102 Heber 1693: 126-127.

103 Ibídem: 127 profunda oscuridad, de manera que no puedan discernirse para ningún fin, y de que tampoco es posible discernir la causa última que la naturaleza de las cosas ha escondido, he adoptado la opinión de que los académicos, y sobre todo los pirrónicos, han empleado la mejor manera de filosofar, oponiendo a cada argumento un contraargumento equivalente, y creyendo además encontrar argumentos de igual peso a ambos lados de cada cuestión. ${ }^{104}$

Éste es uno de los llamamientos más explícitos a seguir las huellas de los antiguos escépticos. Otra característica del escepticismo de Heber era la desconfianza hacia las élites gobernantes. Aunque creía, al igual que la mayoría de las personas de su tiempo, que mucha gente nace para la esclavitud, señalaba que aquellos que gobiernan sobre ellos son deshonestos y generalmente ocultan sus verdaderas opiniones. Además, los gobernantes actúan de acuerdo con la doctrina de los arcana imperii (secretos de Estado), que les permite engañar a la gente ocultando sus acciones. Estas observaciones indican que Heber creía que deberíamos desconfiar profundamente de las autoridades.

Sorprendentemente, nunca se pidió a Heber que rindiese cuentas ante la administración de la universidad, como Thomasius temía que sucediese tras la publicación de este texto. Aparentemente, Heber estaba tan bien integrado en la sociedad de Wittenberg (a pesar de que la despreciara secretamente) que no le ocurrió nada. En 1692, se convirtió en Syndikus de la ciudad, luego en Bürgermeister (alcalde) y, en 1695, en rector de la universidad por segunda vez. ${ }^{105} \mathrm{El}$ suegro de Heber era el recientemente fallecido Johann Andreas Quenstedt, uno de los pilares de la ortodoxia luterana. Quizá nadie se atrevió a acusar de librepensador al yerno de una figura tan prominente de la ortodoxia luterana de Wittenberg.

Sin embargo, Heber no adoptó el papel de reformista radical e ilustrado temprano en Wittenberg que Thomasius pretendía promover. Nunca publicó nada sobre asuntos religiosos. No obstante, el respaldo de Thomasius al escepticismo de Heber formaba parte de su lucha por separar la Iglesia del Estado y poner a los teólogos en su sitio. No habrá lugar para acusaciones de herejía en asuntos políticos si el escepticismo menoscaba las pretensiones de los teólogos de acaparar el conocimiento. El gobernante será libre de tomar sus propias decisiones sobre la herejía si el escepticismo nos pide que rechacemos la autoridad de las personas que aseguran que el conocimiento religioso se extiende también a la política. Asimismo, no habrá motivo para la interferencia del príncipe en asuntos religiosos, siempre que se mantenga la paz y la tolerancia.

En palabras de Hunter, Thomasius se concentraba «en la felicidad terrenal en la sociedad civil». ${ }^{106}$ Su obra proporcionó una alternativa a la modernidad de los derechos y las libertades: la modernidad de un Estado de derecho más bien hobbesiano y una separación entre Iglesia y Estado fundada en el poder de los príncipes o las autoridades civiles. ${ }^{107}$ Pese a que nuestro discurso público actual recurre abundantemente al lenguaje de los derechos y las libertades, es posible que también pueda hallarse

\footnotetext{
104 Ídem.

105 Zedler 1734ff.: vol. 13, col. $1024 f$.

106 Hunter 2007: ix.

107 Ibídem: xi.
} 
un fundamento sólido para la política moderna donde lo habría colocado Thomasius: en el Estado de derecho y la secularización del gobierno.

\section{BiBLIOGRAFÍA}

Ahnert, T. 2006. Religion and the Origins of the German Enlightenment: Faith and the Reform of Learning in the Thought of Christian Thomasius. Rochester: University of Rochester Press.

Bayle, P. 1990. «Sadeur», en Dictionaire historique et critique: 989. Rotterdam. [Reproducido en D. Veiras 1990: 119*].

Gawlick, G. 1989. "Thomasius und die Denkfreiheit», en W. Schneiders (ed.), Christian Thomasius: 1655-1728: 262 y 268. Hamburgo: Meiner.

Heumann, C. A. 1990. De libris anonymis. Jena. [Reproducido en D. Veiras 1990: $122 *-124 *$ ].

Holzhey, H. y Zurbuchen, S. 2001. "Christian Thomasius», en H. Holzhey y W. Schmidt-Biggemann (eds.), Grundriss der Geschichte der Philosophie. Die Philosophie des 17. Jahrhunderts. Band 4: Das heilige Römische Reich der deutscher Nation, Nord und Ostmitteleuropa: 1165-1202. Basilea: Schwabe.

Hunter, I. 2001. Rival Enlightenments. Cambridge: Cambridge University Press.

Hunter, I. 2005. "Thomasius on the Toleration of Heresy», en I. Hunter, J. C. Laursen y C. Nederman (eds.), Heresy in Transition: 155-167. Aldershot: Ashgate.

Hunter, I. 2007. The Secularisation of the Confessional State. Cambridge: Cambridge University Press.

Hunter, I. 2011. "Libertad religiosa y coacción racional: Thomasius y Locke sobre la tolerancia», en M. a J. Villaverde y J. C. Laursen (eds.), Forjadores de la tolerancia:139-140. Madrid: Tecnos.

Israel, J. 2001. Radical Enlightenment: Philosophy and the Making of Enlightenment, 1650-1750. Oxford: Oxford University Press.

Keohane, N. 1980. Philosophy and the State in France. Princeton: Princeton University Press.

Laursen, J. C. 2015. "Christian Thomasius, Theological Skepticism, and Political Conservatism», en E. Argaud, N. El Yadari, S. Charles y G. Paganini (eds.), Pour et contre le scepticisme: Théories et pratiques de l'Antiquité aux Lumières: 193-202. París: Champion.

Laursen, J. C. 2017. "Christian Thomasius as Lawyer for the Atheists: Defending the Author of the History of the Sevarambians», en L. Bianchi, N. Gengoux y G. Paganini (eds.), Philosophie et libre pensée: 403-416. París: Champion.
Laursen, J. C. y Pham, K. 2017. «Empires for Peace: Denis Veiras's Borrowings from Garcilaso de la Vega, el Inca». The European Legacy 22: 427-442.

Masroori, C. 2012. "Toleration in Denis Veiras's Theocracy», en J. C. Laursen y M.a J. Villaverde (eds.), Paradoxes of Toleration in Early Modern Europe: 121-138. Lanham: Lexington.

Mulsow, M. 2017. Radikale Aufklärung in Deutschland 1680-1720. Clandestine Vernunft. Gotinga: Vandenhoeck \& Ruprecht.

Mulsow, M. y Laursen, J. C. (en prensa). «Georg Michael Heber on Legal and (Possibly) Religious Skepticism in Early Enlightenment Germany", en Oxford University Studies in the Enlightenment.

Paganini, G. 2008. Skepsis: Le débat des modernes sur le scepticisme. París: Vrin.

Thomasius, C. (ed.) 1693. Historia sapientiae et stultitiae. Halle.

Thomasius, C. 1689. «Beschreibung der Sevarambes oder der neuerfindenen Sudlands», en Freymüthiger Jedoch Vernunfft und Gesetzmässiger Gedancken: IV, 949-1005. Halle. [Reimpreso con el título Freymüthige, Lustige und Ernsthaffte jedoch Vernunfft und Gesetz-Mässige Gedancken oder Monats-Gespräche, Halle, 1690; Fráncfort: Athenäum, 1972].

Thomasius, C. 1994a [1705]. Fundamenta luris Naturae et Gentium. Madrid: Tecnos. [Traducido como Fundamentos de derecho natural y de gentes, J. J. Gil Cremades (ed.)].

Thomasius, C. 1994b. De los prejuicios y otros escritos. Madrid: Facultad de filosofía de la Universidad Complutense. [M. a L. P. Cava (ed.)].

Thomasius, C. 1998. Historia algo más extensa del derecho Natural. Madrid: Tecnos. [Ed. Juan José Gil Cremades].

Thomasius, C. 2007. Essays on Church, State, and Politics. Indianápolis: Liberty Fund. [I. Hunter, T. Ahnert y F. Grunert (eds.)].

Thomasius, C. 2011. Institutiones jurisprudentiae divinae. [Leipzig, 1688 (edición de 1730 reimpresa en Aalen: Scientia, 1994)]. [Traducido como Institutes of Divine Jurisprudence. Indianápolis: Liberty Fund. Trad. de T. Ahnert.].

Tomasoni, F. 2009. Christian Thomasius: Geist und kulturelle Identität an der Schwelle zur europäischen Aufklärung. Münster: Waxmann.

Veiras, D. 1990. Eine Historie der neu-gefundenen Völcker Sevarambes genannt 1689. Tubinga: Niemeyer. [W. Braungart y J. Golawski-Braungart (eds.)].

Veiras, D. 2006. The History of the Sevarambians. Albany: State University of New York Press. [J. C. Laursen y C. Masroori (eds.)].

Würtz, J. P. 1981. «Tschirnhaus und die Spinozismus-Beschuldigung: die Polemik mit Christian Thomasius». Studia Leibnitiana 13: 61-75.

Zedler, J. H. 1732ff. Grosses vollständiges Universal-Lexicon. Leipzig y Halle. 